\title{
Degradation of Microcystin LR, Oxytetracycline and Amphicillin by Four Native Bacteria Species
}

\author{
P.S. Dharmadasa, G.Y. Liyanage and P.M. Manage* \\ CentreforWaterQuality andAlgaeResearch,Department ofZoology, University ofSriJayewardenepura, \\ SriLanka
}

Date Received: 07-08-2017 Date Accepted: 02-12-2017

\begin{abstract}
Pollution reaches its most serious proportion in past few decades and adverselyeffect on animals and human health. Reduction of pollutant in the environment take place with microbial metabolism and remediation studies by microbes have proved their feasibility on clean up the contaminated environment. Thus, the present study reports the biodegradation of Micocystins (MC-LR) and antibiotics [Oxytetracycline (OTC) and Ampicillin (AMP)] by Bacillus cereus, Enterobacter ulcerans, Enterobacter sp. and Micrococcus sp. strains which were previously reported as potential crude oil degraders. A $0.5 \mathrm{ml}$ of overnight starved bacterial suspensions was introduced into medium containing antibiotic (OTC, AMP) at $60 \mu \mathrm{g} / \mathrm{ml}$ and Microcystin-LR at $10 \mu \mathrm{g} / \mathrm{ml}$ respectively. Triplicate samples were incubated at $28^{\circ} \mathrm{C}$ while shaking at $100 \mathrm{rpm}$. A $0.5 \mathrm{ml}$ of aliquots was removed at 2 days interval for a period of 14 days and analysis was done by High Performance Liquid Chromatography (HPLC). The highest degradation of MC- LR was shown by Micrococcus sp. (97\%) where as other stains; E. ulcerans (96\%), Enterobactor sp. $(95 \%)$ and $B$. cereus $(88 \%)$ also showed comparative high degradation after 14 days of incubation. $B$. cereus, Enterobacter sp. and Micrococcus sp. were identified as AMP resistance bacteria and degraded AMP at $81 \%, 22 \%$ and $39 \%$ respectively. It was found that B. cereus was resistance to OTC and showed $56 \%$ reduction at 14 days of incubation. The results of the present study revealed that the bioremediation potential of harnessing microbes can cleanup of pollutant in the environment and use as ecofriendly tool for removal of environmental pollutants.
\end{abstract}

Keywords:Bacillus cereus, Enterobactersp., Enterobacter ulcerans, Micrococcus sp.,Antibiotics, Microcystin

\section{Introduction}

In the last few years a large number of ecosystems have changed due to anthropogenic activities. Petroleum hydrocarbons, microcystin, pharmaceuticals are different type of toxicants in the environment and have become one of the most serious environmental problems around the world(Fereidoun et al., 2007). These contaminates can accumulate via food chain and persist in the environment for a long time. Those pollutants reaches its most serious proportion in the densely settled urban-industrial centers of more developing countries (Kromm, 1973; Havens et al., 2003).

*Correspondence: pathmalal@sjp.ac.lk

Tel: +94714463908

ISSN 2235-9370 Print/ISSN 2235-9362 Online @ C University of Sri Jayewardenepura 
Occurrence of pharmaceuticals, especially antibiotics in the aquatic environment is a wellestablished issue and has become a matter of both scientific and public concern (Allen et al., 2010). The introduction of these compounds into the environment through anthropogenic sources can constitute a potential risk for aquatic and terrestrial organisms. Although present at vestigial levels, antibiotics may cause resistance in bacterial populations, making them ineffective in the treatment of several diseases (Baquero et al., 2008; Liyanage and Manage, 2016 c). Several studies have reported the occurrence of antibiotic residues in aquatic ecosystems: surface waters, drinking water, water treatment plant effluents and hospital wastewaters (Berglund et al., 2014; Liyanage and Manage 2015 c, 2016 b).

Further, over the past several centuries, nutrient enrichment in water, particularly nitrogen and phosphorus, associated with urban, agricultural and industrial development, has promotedincreaseof cyanobacteria which cause eutrophication. This condition favors the mass occurrence of cyanobacterial blooms where cyanobacterial cells grow exuberantly, and reach more than 10,000 cells per milliliter (Manage et al., 2009).Cyanobacteria are the distinct group of bacteria which are photosynthetic and produce several metabolites. These metabolites include several endotoxins known to be cyanotoxins which are commonly found during blooms of cyanobacteria (Manage et al.,2010).

Cyanobacteria may produce toxins such as hepatotoxic peptides, neurotoxic alkaloids and dermatotoxic phenolic compounds, in addition to lipopolysaccharides (Sivonen et al., 1990). Microcystinis a group of cyclic heptapeptidehepatotoxins, which are produce by some strains of cyanobacteriaum, Microcystis spp., Anabaenaspp., Oscilatoriaspp.(Romanowska-Duda et al., 2002). These substances are natural endotoxins and release into water in high concentration when cell lysis takes place. (Manage et al., 2000;Romanowska-Duda et al., 2002). Cell lysis occurs under stress, mostly because of natural mortality or algaecide treatments. This cyclic heptapeptide causes serious damage to liver architecture, cellular organelles and reorganization of microfilaments. They inhibit the activity of protein phosphate 1 and 2A and act as tumor promoters(Zhao et al., 2006).

The mechanical and chemical methods that are used to remove antibiotics and Microcystin from contaminated sites have limited effectiveness and are not accessible to all parts of the world due to high operating and material costs (Liyanage and Manage 2016 b, Idroos and Manage, 2014, Manage et al., 2009).Bioremediation is one of the most promising technologies for the treatment of antibiotics and Microcystin as it is cost effective and identified as the best alternative eco-friendlymethod (Liyanage and Manage, 2015 b., Manage et al., 2009). In bioremediationspecific bacteriause to remove either specific type of contaminant or different type of contaminants. A number of studies have reported biological degradation of microcystin in samples collected from lakes and sediments (Manage et al., 2009; Manage et al., 2010), but only a few bacterial strains with the ability to degrade microcystins have been isolated and characterized. For instance, many of the MC degraders are reported as Sphingomonasor Sphingomonas. Until Manage et al. (2009), identified MC degrading Gram-positive Actinobacteria, all of the MC degraders had belonged to Gram-negative Proteobacteria.

In degradation of antibiotics; Ding et al (2016) reported the tolerance of Acinetobacter, Stenetrophomonasmaltophilia and Aeromonasveronii to OTC in freshwater environments of Ireland and England. Maki et al., (2006) has isolated flavobacterium strains responsible for the degradation of a group of antibiotics including OTC and AMP. Liyanage and Manage (2016a; 2015a.) reported the antibiotic resistance activity by bacterial strain Enterococcus sp., Acinetobacter sp.

Thus, present study was focused on the Microcystin and Antibiotics degradation feasibility of Bacillus cereus, Enterobacter sp., Micrococcus sp. and Enterobacter ulcerans stains, since very limited information is available regarding multiple pollutant degradation ability of bacteria in Sri Lanka. These four stains were previously reported to be degraders of crude oil (Liyanage and Manage, 2016b). 


\section{Material and method}

2.1 Chemicals and reagents

OTC and AMP standards, HPLC and Bacteriological grade chemicals were purchased from Sigma Aldrich, USA.

\subsection{Preparation of bacterial cultures}

Each bacterial stain was transferred into $5 \mathrm{ml}$ of liquid Luria Bertani (LB) medium and incubated $28^{\circ} \mathrm{C}$. Then followed centrifugation to remove carbon source from the LB media and then the bacteria suspension was subjected to the starvation procedure, in phosphate buffer solution (PBS). Thereafter equalized the turbidities of the bacteria suspension at A 590=0.35 (Manage et al., 2009; Liyanage and Manage 2016).

\subsection{Microcystin degradation}

A $0.5 \mathrm{ml}$ of starved, equalized bacterial suspension was inoculated into filtered sterilized lakewater containing microcystin at a final concentration of $10 \mu \mathrm{g} / \mathrm{ml}$. The treated flasks were incubated at

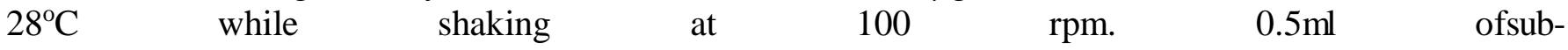
sampleswerecollectedattwodaysintervalsforaperiodof14days. Thenthesubsamples were centrifuged (12000 $\mathrm{rpm}$ )and the supernatantofeachsamplewassubjected toimmediatefreezing and stored at $-20^{\circ} \mathrm{C}$ (Manage et al., 2010). Then the frozen samples were freeze-dried and reconstituted in $1 \mathrm{ml}$ of $100 \%$ aqueousHPLCgrademethanolandsubjectedtotheHPLCanalysis (Idroos and Manage, 2014). The control was treated in the same manner as the experiment without bacterial inoculation. All the experimentswere done for each tested bacterial strain.

\subsection{Analysis of MC-LR by HPLC}

MC-LR analysis was carried out by using the HPLC system consisting of Agilent 1200 series following the modified method of Manage et al (2009). The injected volume was $25 \mathrm{ul}$ at $30^{\circ} \mathrm{C}$. The $\mathrm{C}_{18}$ column was used and the eluents solvent were deionized water $-0.05 \%$ trifluoroacetic acid (TFA) and acetonititrile $-0.05 \%$ trifluoroacetic acid (TFA). Concentration of MC-LR was determined by calibration of the peak areas in 200-330 $\mathrm{nm}$. TheHPLC method hasadetectionlimitof0.5 $\mu \mathrm{g} / \mathrm{ml}$ and MC-LR recovery was obtainedgreaterthan90\% (Manage et al., 2010).

\subsection{Antibiotic degradation experiment for bacteria isolates}

A $0.5 \mu \mathrm{l}$ of equalized bacterial suspension was inoculated into filter-sterile freshwater, containing antibiotic at a final concentration of $60 \mu \mathrm{g} / \mathrm{ml}$ respectively. All flasks were incubated at $28^{\circ} \mathrm{C}$ with continuously shaking at $100 \mathrm{rpm}$. A $0.5 \mathrm{ml}$ of sub samples were collected at two days intervals for a period of 14 days (Liyanage and Manage 2016 b). Then the subsamples were centrifuged (12000 rpm) and supernatant of each sample was subjected immediate freezing and stored at $-20^{\circ} \mathrm{C}$. Then the frozen samples were freeze-dried and reconstituted in $1 \mathrm{ml}$ of $100 \%$ aqueous HPLC grade methanol and subjected to the HPLC analysis. Control samples were prepared in triplicates following same protocol without bacteria inoculation (Liyanage and Manage. 2016 a).

\subsection{Minimum Inhibition Concentration}

The Minimum Inhibition Concentration (MIC) was determined by using an agar dilution method according to CLSI guidelines (CLSI.2015).

\subsection{Analysis of antibiotics by HPLC}

The target antibiotics were quantified by using Agilent 1200 series HPLC equipped with diode array and fluorescence detector (Fernandez-Torres et al., 2010; Liyanage and Manage, 2016 b). The 
injected volume was $20 \mu \mathrm{l}$ and chromatography was performed at $30^{\circ} \mathrm{C}$. The mobile phase considered of a mixture of $0.1 \%$ Glacial acetic acid in water (Component A): $0.1 \%$ Glacial acetic acid in acetonitrile (Component B), 99:1 (v/v) was pumped in beginning at a flow rate of $0.7 \mathrm{ml} / \mathrm{min}$ for OTC and TET. Then followed linear elution gradient from $99 \%$ to $70 \% \mathrm{~A}$ in $25 \mathrm{~min}$ for the above antibiotics (Liyanage and Manage, 2016 b). Concentration of each antibiotic was determined by calibration of the peak areas (at 280 $\mathrm{nm}$ for OTC, $230 \mathrm{~nm}$ for AMP) with that of an external standard. OTC and AMP recoveries were greater than $90 \%$.

\subsection{Determination of degradation rate and half-life time}

The degradation rate (h) of antibiotic/MC-LR by bacteria was calculated according tothe equation given bellow.Half life time was calculated as the time taken to degrade $50 \%$ of antibiotic/MC-LR from the initial concentration.

$h=\ln \left(C / C_{0}\right) / t$

Where:

$\mathrm{CO}=$ theconcentration of antibiotic/MC-LR at the beginning

$C=$ theconcentration of antibiotic/MC-LRat the end of the time interval trespectively (Manage et al, 2000).

\section{Results}

\subsection{Microcystin-LR degradation kinetics}

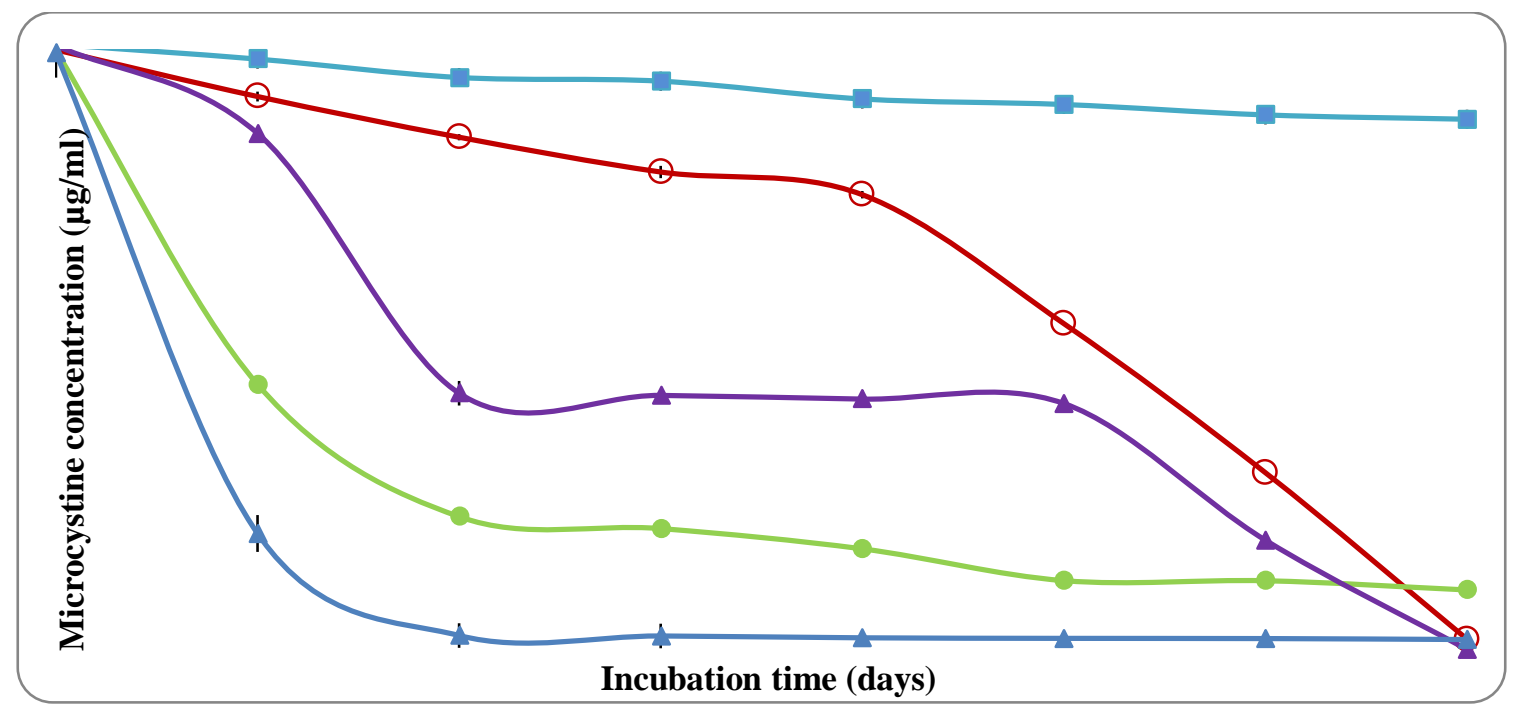

Figure 1: Microcystin-LR (MC-LR) degradation by four bacterial strains after 14 days of incubation at 28 ${ }^{\circ} \mathrm{C} \pm 1{ }^{\circ} \mathrm{C}$. When error bars are not shown standard error was less than the width of the symbol. (Closed square; control, open circle; Enterobacter sp., closed circle; B. cereus, open triangle; Micrococcus sp., closed triangle; E.ulcerans).

Figure 1 showed the degradation of MC-LR by different bacterial strains. At 4 days of the incubation Micrococcus sp. showed significant degradation, after that remaining constant until day 10 and thereafter decreased up to $97 \%$. In contrast, Enterobacter sp. maintained gradual decrease of MC-LR by day 8 of incubation and then initiated rapid degradation and ended up with achieving $98 \%$ degradation at 14 days of incubation. B. cereus only showed $82 \%$ of degradation even at 14 days of incubation. Analysis 
of the sterile controls showed no significant loss of MC-LR during the incubation and only $9 \%$ of decrease was detected may due to natural degradation and photo degradation effect.

Table 1:Rate of degradation in MC-LR (given as mean value of triplicates).

\begin{tabular}{ccccc}
\hline Incubation & \multicolumn{4}{c}{ Degradation rate $\left(\mathrm{d}^{-1}\right)$} \\
\cline { 2 - 5 } time (Days) & Enterobacter $\mathrm{sp}$. & B. cereus & Micrococcus $\mathrm{sp}$. & E. ulcerans \\
\hline 0 & $0 \pm 0.000$ & $0 \pm 0.000$ & $0 \pm 0.000$ & $0 \pm 0.000$ \\
2 & $0.04 \pm 0.02$ & $0.39 \pm 0.04$ & $0.07 \pm 0.02$ & $0.77 \pm 0.01$ \\
4 & $0.04 \pm 0.01$ & $0.36 \pm 0.06$ & $0.20 \pm 0.04$ & $0.76 \pm 0.05$ \\
6 & $0.04 \pm 0.03$ & $0.25 \pm 0.04$ & $0.14 \pm 0.02$ & $0.51 \pm 0.02$ \\
8 & $0.03 \pm 0.05$ & $0.21 \pm 0.02$ & $0.10 \pm 0.05$ & $0.39 \pm 0.03$ \\
10 & $0.06 \pm 0.06$ & $0.19 \pm 0.01$ & $0.08 \pm 0.01$ & $0.31 \pm 0.02$ \\
12 & $0.10 \pm 0.06$ & $0.17 \pm 0.01$ & $0.13 \pm 0.04$ & $0.26 \pm 0.04$ \\
14 & $0.23 \pm 0.04$ & $0.16 \pm 0.02$ & $0.26 \pm 0.02$ & $0.22 \pm 0.02$ \\
\hline
\end{tabular}

E. ulcerans showed the highest degradation rates at second day of incubation $\left(0.77 \pm 0.01 \mathrm{~d}^{-1}\right)$ where as other strains showed low degradation rates during first two days. The degradation rates of Enterobacter sp. were more or less constant $\left(\sim 0.04 \pm 0.02 \mathrm{~d}^{-1}\right)$ up to day 10 and thereafter increased significantly up to $0.23 \pm 0.04 \mathrm{~d}^{-1}$ at 14 days of incubation. B. cereus showed high degradation rate $\left(0.39 \pm 0.04 \mathrm{~d}^{-1}\right)$ at the beginning and pronounced gradual decrease was observed onwards. Micrococcus sp. showed higher degradation rate at end of the 14 days of incubation $\left(0.26 \pm 0.02 \mathrm{~d}^{-1}\right)$.

Table 2:Half life time of the MC-LR degradation by four bacteria strains.

\begin{tabular}{lc}
\hline Name of the bacteria & Half life time (days) \\
\hline Enterobacter $\mathrm{sp}$. & 10.5 \\
B. cereus & 1.8 \\
Micrococcus $\mathrm{sp}$. & 3.7 \\
E. ulcerans & 1.3 \\
\hline
\end{tabular}

E. ulcerans showed the lowest half life time of 1.3 days of incubation whereas B. cereus and Micrococcus sp. showed 1.8 and 3.7 days respectively. A half life time of 10.5 days were detected for Enterobacter sp.

Antibiotic degradation kinetics

Resistance of the bacteria to tested antibiotics

Table 3:Antibiotic resistant against Oxytetracycline and Ampicillin by the tested bacterial strain.

\begin{tabular}{lcc}
\hline Bacteria & Oxytetracycline (OTC) & Ampicillin (AMP) \\
\hline Enterobactersp. & - & + \\
B. cereus & + & + \\
Micrococcus sp. & - & + \\
E. ulcerance & - & - \\
\hline
\end{tabular}

(+) resistance(-) not resistance. 
The bacteria resistance for the $60 \mu \mathrm{g} / \mathrm{ml}$ concentration of OTC and AMP was recorded in table 3. Only B. cereus was resistance to OTCwhereasEnterobacter sp., B. cereus, Micrococcus sp. were recorded as resistance strain of bacteria for AMP.

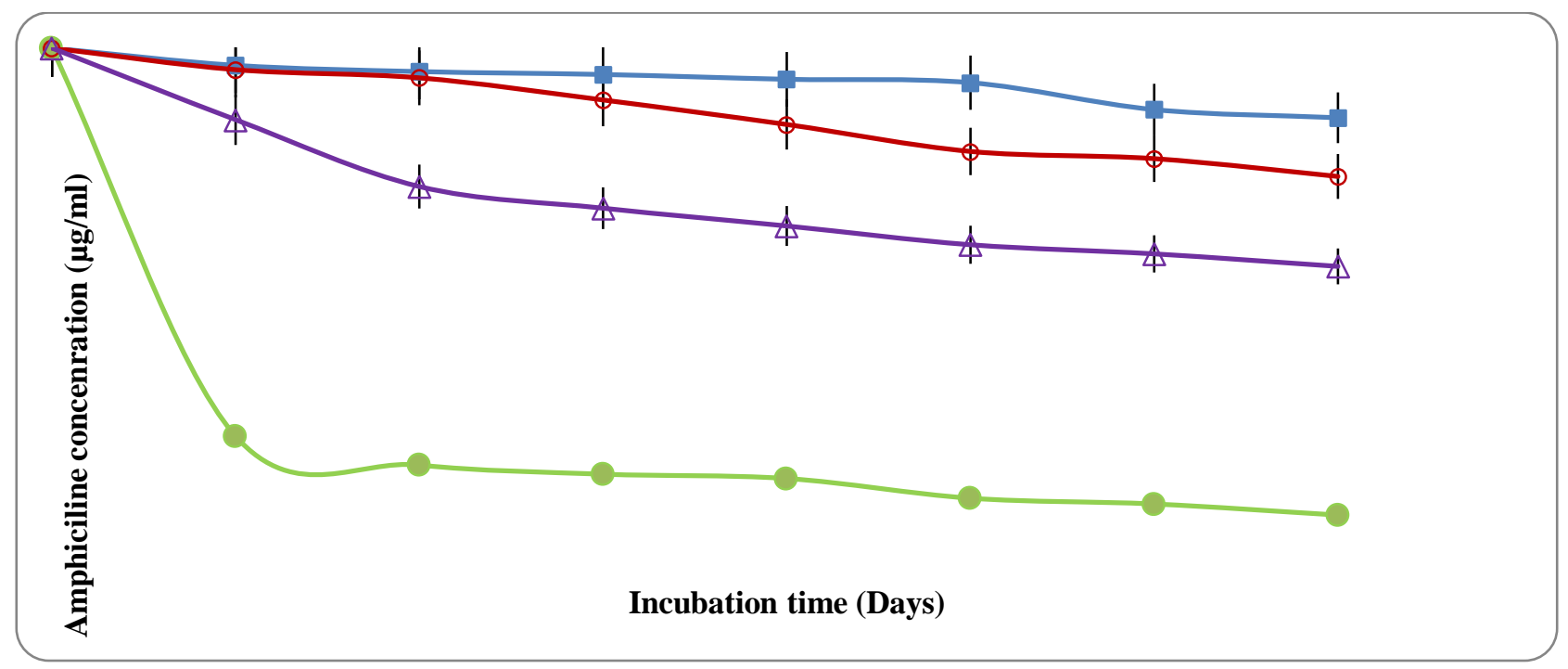

Figure 2: Degradation of AMP by three native bacterial strains, which are resistance to AMP.When error bars are not shown standard deviation was less than the width of the symbol. (Closed square; control, open circle; Enterobacter sp., closed circle; B. cereus, open triangle; Micrococcus sp.).

Figure 2 shows the degradation of AMP $(60 \mu \mathrm{g} / \mathrm{ml})$ by bacterial strains during the incubation period. The AMP resistance bacteria; B. cereus, Enterobacter sp. and Micrococcus sp. were showed $81 \%$, $22 \%, 39 \%$ degradation of AMP respectively at 14days of incubation. Except B. cereus, other two bacterial strains were not showed a significant degradation thus it was not possible to calculate half life time during the incubation. Half life time ofAMP for B. cereus was 1.5 days and it was identified as a potential AMP degrader among the bacteria strains employed in the present study.

Table 4:Degradation rate of Ampicillin in $60 \mu \mathrm{g} / \mathrm{ml}$ (given as mean value of triplicate).

\begin{tabular}{cccc}
\hline Incubation & \multicolumn{3}{c}{ Degradation rate $\left(\mathrm{d}^{-1}\right)$} \\
\cline { 2 - 4 } time (Days) & Bacillus cereus & Enterobacter $\mathrm{sp}$. & Micrococcus $\mathrm{sp}$. \\
\hline 0 & $0 \pm 0.000$ & $0 \pm 0.000$ & $0 \pm 0.0000$ \\
2 & $0.56 \pm 0.014$ & $0.02 \pm 0.007$ & $0.07 \pm 0.001$ \\
4 & $0.32 \pm 0.005$ & $0.01 \pm 0.001$ & $0.07 \pm 0.007$ \\
6 & $0.22 \pm 0.025$ & $0.01 \pm 0.012$ & $0.05 \pm 0.000$ \\
8 & $0.17 \pm 0.002$ & $0.02 \pm 0.016$ & $0.05 \pm 0.007$ \\
10 & $0.15 \pm 0.035$ & $0.02 \pm 0.000$ & $0.04 \pm 0.014$ \\
12 & $0.13 \pm 0.005$ & $0.02 \pm 0.014$ & $0.04 \pm 0.000$ \\
14 & $0.11 \pm 0.032$ & $0.02 \pm 0.007$ & $0.03 \pm 0.014$ \\
\hline
\end{tabular}

B. cereus showed highest degradation rate $\left(0.56 \pm 0.014 \mathrm{~d}^{-1}\right)$ after two days of incubation while Enterobactersp. and Micrococcus sp. showed $0.02 \pm 0.007 \mathrm{~d}^{-1}$ and $0.07 \pm 0.001 \mathrm{~d}^{-1}$ degradation after two days of incubation respectively. 


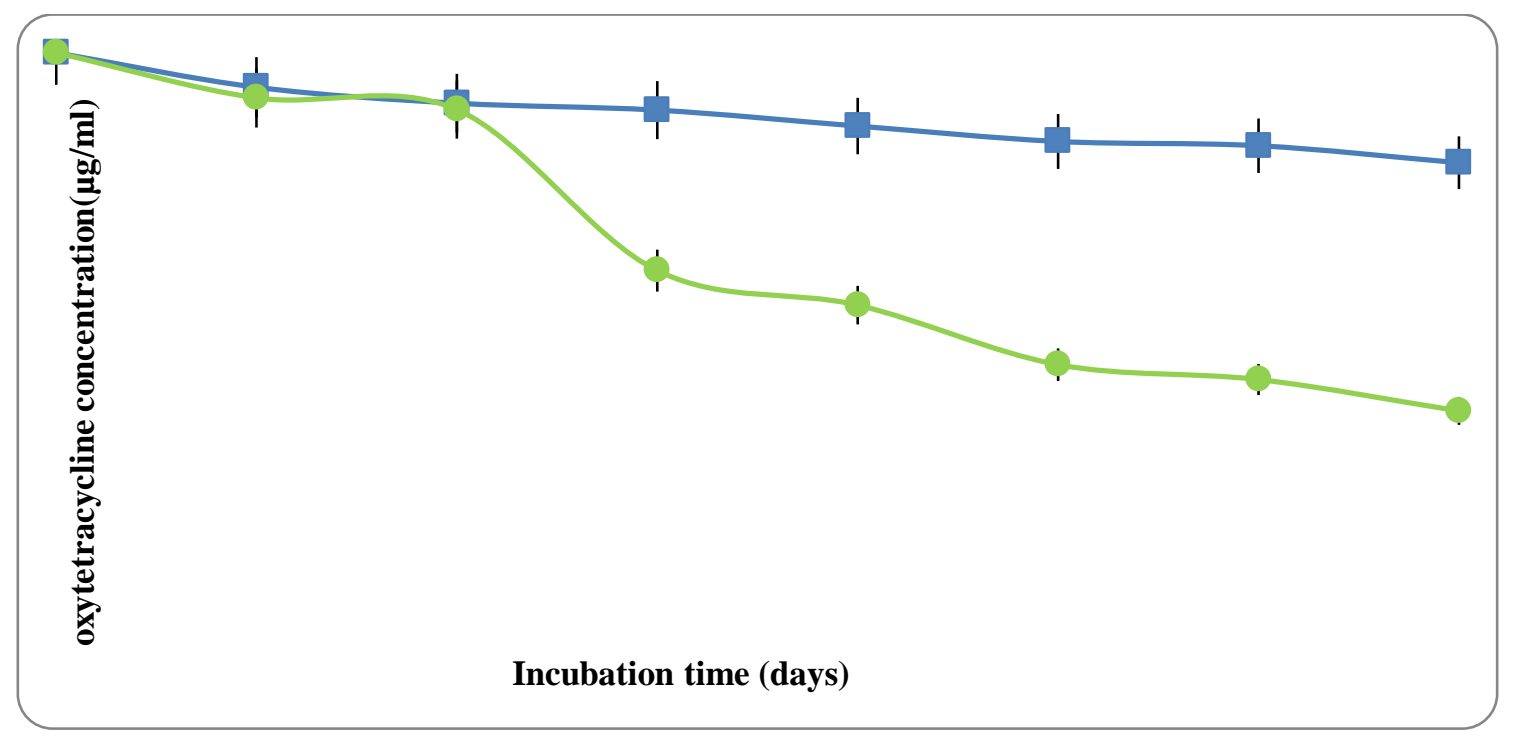

Figure 3:Degradation of OTC by B. cereus. The error bars are not shown standard deviation was less than the width of the symbol. (Closed square; control, closed circle; B. cereus).

Figure 3 showed the degradation of OTC $(60 \mu \mathrm{g} / \mathrm{ml})$ by B. cereus which was the only strain recorded to resistant againstOTC. After 14 days incubation at $28 \pm 1^{\circ} \mathrm{C}$ the bacterial strains achieved $56 \%$ reduction of OTC.

Table 5: Rate of degradation in Oxytetracycline by B. cereus

(given as mean value of triplicate).

\begin{tabular}{cc}
\hline Days & Degradation rate $\left(\mathrm{d}^{-1}\right)$ \\
\hline 0 & $0 \pm 0.0000$ \\
2 & $0.04 \pm 0.004$ \\
4 & $0.02 \pm 0.004$ \\
6 & $0.07 \pm 0.002$ \\
8 & $0.06 \pm 0.006$ \\
10 & $0.07 \pm 0.002$ \\
12 & $0.06 \pm 0.003$ \\
14 & $0.06 \pm 0.009$ \\
\hline
\end{tabular}

Low degradation rate was detected until day 4 of incubation $\left(0.02 \pm 0.004 \mathrm{~d}^{-1}\right)$ where as it was increased up to $0.07 \pm 0.002 \mathrm{~d}^{-1}$ at $6^{\text {th }}$ day of incubation.

\section{Discussion}

Present study reports the biodegradation of some peptides (microcystins and some antibiotics) by four native bacteria species namely B. cereus, E. ulcerans, Enterobacter sp. and Micrococcus sp. The bacteria species were previously isolated from soil and water from three distinguishes cites where exposed to crude oil contamination with regular shipping activities and reported as degraders of crude oil (Liyanage and Manage, 2016).

There is a growing number of isolated organisms reported as having the ability to degrade microcystin in water and so far the majority of bacteria appears belonging to the class proteobacteria(Havens et al., 2003). However, Manage et al., (2009) reported actinobacteria species as 
microcystindegraders. In the present study four bacterial isolates were shown significant degradation of microcystin-LR (MC-LR) at 14 days incubation. At 2 days incubation significant degradation of MC-LR was achieved by E. ulcerans (78\%) and B. cereus (54\%). At 4 days of the incubation Micrococcus sp. (56\%) showed significant degradation of MC-LR (Figure 3). Several studies were reported that Bacillus spp. as micosystine degrading bacteria (Zhoa et al., 2006). Bacillus sp. utilize microcystineas sole carbon source and concentration of microcystine become zero within 7 days according to Enzyme Linked Immunosorbant Assay (ELISA) and within 8 days according to protein phosphatase inhibition assay (Alamri, 2013). Accordingly the present study B. cereus degraded 88\% of MC-LR after 14 days incubation and E. ulcerans (96\%), Enterobactor sp. (95\%) and Micrococcus sp. (97\%) have ability to degrade high amount of MC-LR(Figure 3) compare to the other bacterial strains. Out of the four strains $E$. ulcerans was shown short half-life (1.3 days) for MC-LR (Table 1) compared to other three bacteria species employed in the present study.

Antibiotics are considered as emerging micro contaminants in water due to their potential adverse effects on ecosystems and human health. Major negative effect of high concentration of antibiotics in the environment is developing antibiotic resistance bacterial species and those bacteria become more virulent (Tan et al., 2012). Antibiotic resistance can occur via three general mechanisms: prevention of interaction of the drug with target, efflux of the antibiotic from the cell, and direct destruction or modification of the compound(Samah et al., 2006). The WHO has recommended a guide line value of less than $1 \mu \mathrm{g} / \mathrm{l}$ of antibiotic residues in the aquatic environment and less than $100 \mu \mathrm{g} / 1$ in soil respectively (WHO, 2015). Liyanage and Manage (2015 c.) recorded that both water and sediment samples collected from wastewater discharge points in Sri Lanka contains higher OTC $(0.664-0.841 \mu \mathrm{g} / \mathrm{ml})$ and AMP $(0.115-0.139 \mu \mathrm{g} / \mathrm{ml})$ levels than the recommended values given by the WHO. Therefore it causes an increase of antibioticresistant bacteria. Accordingly present studyB. cereus is resistance to OTC and the testedother bacteria species were resistance to AMP except E. ulcerans.

B. cereus, Enterobactor sp. and Micrococcus sp. showed 81\%, 22\%, 39\% degradation of AMP respectively. B. cereus was shown highest degradation and it was found that the $B$. cereuswas the only bacteria specie showed $56 \%$ reduction of OTC at 14 days incubation.

Hence introduction, establishment and development of such ecofriendly, cost effective bio technologies for the country is timely important to help for the development of the country. The results of the present study revealed that the bioremediation technology with harnessing microbes will provide sound information for the cleanup of pollutant in the environment as ecofriendly tool for green solution. Further studies with combination of biotechnology approaches are needed to development of eco friendly methods for cleanup environmental pollutants.

\section{Conclusions}

The highest degradation of MC- LR was shown by Micrococcus sp. (97\%) where as other stains; E. ulcerans $(96 \%)$, Enterobactor sp. (95\%) and B. cereus (88\%) also showed comparative high degradation after 14 days of incubation. B. cereus, Enterobacter sp. and Micrococcus sp. were identified as AMP resistance bacteria and degraded AMP at $81 \%, 22 \%$ and $39 \%$ respectively. It was found that $B$. cereus was resistance to OTC and showed $56 \%$ reduction at 14 days of incubation. The results of the present study revealed that the bioremediation potential of harnessing microbes can cleanup of pollutant in the environment and use as eco friendly tool for removal of environmental pollutants. 


\section{References}

Allen, H. K., Donato, J., Wang, H. H., Cloud-hansen K. A., Davies, J. and Handelsman J. 2010. Call of the wild: antibiotic resistance genes in natural environments. Nat. Rev Microbio. 8(4):251-259.

Alamri, S. A. 2013. Biodegradation of microcystin by a new Bacillus sp. isolated from a Saudi freshwater lake. African Journal of Biotechnology, 9, 6552-6559.

Berglund, B., Khan, G.A., Weisner, S. E., Ehde, P.M., Fick, J. and Lindgren, P.E. 2014. Efficient removal of antibiotics in surface-flow constructed wetlands, with no observed impact on antibiotic resistance genes. Science of the Total Environment. 476:29-37.

Baquero, F., Martnez, J.L. and Cantn, R. 2008. Antibiotics and antibiotic resistance in water environments. Current Opinion in Biotechnology.19(3):260-265.

CLSI guide lines. 2015. Available at; http://clsi.org/wp-content/uploads/sites/14/2013/07/CLSI-2015Catalog.pdf

Ding, H., Wu, Y., Zou, B., Lou, Q., Zhang, W. and Zhong J. 2016. Simultaneous removal and degradation characteristics of sulfonamide, tetracycline, and quinolone antibiotics by laccase-mediated oxidation coupled with soil adsorption. Journal of hazardous materials. 307:350-358.

Idroos, F.S. and Manage, P.M. 2014. Evaluation of antibiotic degrdation feasibility of Bacillus cereus and Rahnellaaquatilisstrains , Journal of Environment and Natural Resources, Thailand. 188-193.

Fernandez-torres, M.O., Consentino, M.A., Bello lopez. and Larsen, J.L. 2010. Simultaneous determination of 11 antibiotics and their main metabolites from four Different groups by reversedphase high performance liquid chromatography-diode array -fluorescence (HPLC-DAD-FLD) in human urine sample.Talanta. 81:871-880.

Fereidoun, H., Nourddin, M.S., Rreza, N.A., Mohsen, A., Ahmad, R. and Pouria, H. 2007. The effect of long-term exposure to particulate pollution on the lung function of Teheranian and Zanjanian students. Pakistan Journal of physiology. 3:1-5.

Havens, K.E., James, R.T., East, T.L. and Smith, V.H. 2003. N: P ratios, light limitation, and cyanobacterial dominance in a subtropical lake impacted by non-point source nutrient pollution. Environmental Pollution. 122:379-390.

Kromm, D.E. 1973. Response to air pollution in ljubljana, yugoslavia. Annals of the association of American Geographers. 63:208-217.

Liyanage, G.Y. and Manage. P.M. 2016 a. Isolation and Characterization of Oil Degrading Bacteria from Coastal Waters and Sediments in Sri Lanka. J.Natn.Sci.Foundation Sri Lanka, 44 (4): 351 - 358

Liyanage, G.Y. and Manage. P.M. 2016 b. Risk of prophylactic antibiotics in livestock and poultry farms; a growing problem for human and animal health and for the environment. Proceeding of $2^{\text {nd }}$ Environment and Natural Resources International Conference. Thailand. pg 20.

Liyanage, G. Y., and Manage, P. M. 2016 c. Evaluation of Amoxicillin and Sulfonamide removal by Bacillus cereus, Enterobacterludwigii and Enterobacter sp., Environment and Natural Resources J., 14 (1): 39-43

Liyanage. G.Y. and Manage. P.M. 2015 (a). Presence of Tetracycline and Oxytetracycline Resistant Bacteria and Resistant Genes in Effluent Water of Zoological Garden, Sri Lanka. Proceeding of 11th International Academic Conference on Development in Science and Technology (IACDST2015). 11-14.

Liyanage. Y. and Manage. P.M. 2015 (b). Evaluation of Amoxicillin and Sulfanomide removal by $B$. cereus, E. ludwigii and Enterobacter sp. Journal of Environment and Natural Resources, 14: 4339-4343.

Liyanage, G.Y., Manage, P.M. and De Alwis, A. (2015.c) Study on the occurrence of Antibiotic Contaminations in the Aquatic Environment, Sri Lanka. International Conference on Multidisciplinary Approaches Proceeding, Pg. 198. 
Maki, T., H. Hasegawa, H. Kitami, K. Fumoto,Munekage, Y. and Ueda. K. 2006.Bacterial degradation of antibiotic residues in marine fish farm sediments of uranouchi bay and phylogenetic analysis of antibiotic-degrading bacteria using 16s rDNA sequences. Fisheries science., 72: 811 - 820.

Manage, P.M., Chritine Edwards and Linda A Lawton. 2009. Biodegradation of Microcystin LR by natural bacterial population. Environmental Research in Asia TERRAPUB, (2009)Vol. 2 277-285

Manage, P.M., C. Edwards and Lawton. L. 2010. "Bacterial degradation of microcystin." Interdisciplinary Studies on Environmental Chemistry-Biological Responses to Contaminants. TERRAPUB: Tokyo: 97-104.

Manage, P.M., Zen ichiro Kawabata and Shin-ichi Nakano. 2000. Algicidal effect of the bacterium Alcaigenesdenitrificans onMicrocystisspp. AquatMicrobEcol 22: 111-117.

Romanowska-Duda, Z., Mankiewicz, J., Tarczynska, M., Walter, Z. and Zalewski, M. 2002. The effect of toxic cyanobacteria (blue-green algae) on water plants and animal cells. Polish Journal of Environmental Studies, 11, 561-566.

Sarmah, A. K., Meyer, M. T., and Boxall, A. B. 2006. A global perspective on the use, sales, exposure pathways, occurrence, fate and effects of veterinary antibiotics (VAs) in the environment. Chemosphere., 65(5): 725-759.

Sivonen, K., Niemelä, S., Niemi, R., Lepistö, L., Luoma, T. and Räsänen, L. 1990. Toxic cyanobacteria (blue-green algae) in Finnish fresh and coastal waters. Hydrobiologia, 190, 267-275.

Tan, Z., Tan, F., Zhao, L. and Li, J. 2012. The Synthesis, Characterization and Application of Ciprofloxacin Complexes and Its Coordination with Copper, Manganese and Zirconium Ions. Journal of Crystallization Process and Technology, 2(02), 55.

World Health Organization, 2015. Global action plan on antimicrobial resistance. p.Geneva: World Health Organization. Available at: http://www.who.int/drugresistance/global action plan/en/.

Zhao, Y.-Y., Hrudey, S. and LI, X.-F. 2006. Determination of Microcystins in Water Using Integrated Solid-Phase Microextraction with Microbore High-Performance Liquid ChromatographyElectrospray Quadruple Time-of-Flight Mass Spectrometry. Journal of chromatographic science, 44, 359-365. 